\title{
Pensamento Computacional em Atividades de Robótica Pedagógica Livre no Ensino Médio
}

\author{
Anderson Silva Gusmão1, Rozelma Soares de França1 \\ ${ }^{1}$ Universidade Federal Rural de Pernambuco (UFRPE) \\ 52171-900 - Recife - PE - Brasil \\ \{andergusmao, rozelma.soares\} @gmail.com
}

\begin{abstract}
Based on constructionism, this paper describes an experience of exploration of computational thinking through Free Pedagogical Robotics in a state public school in Pernambuco. This experience presents itself as a methodological possibility for the construction of Computer Science knowledge, linked to curricular contents, in basic education. Rather than developing and improving algorithmic thinking skills, they are considered social aspects in the production of knowledge and in relation to students. Throughout the text, the activities carried out are summarized, as well as their results.
\end{abstract}

Resumo. Baseado no construcionismo, neste trabalho é descrito um relato de experiência de exploração do pensamento computacional por meio da Robótica Pedagógica Livre em uma escola pública estadual de Pernambuco. Esta vivência apresenta-se como uma possibilidade metodológica para construção de conhecimentos de Computação, atrelado a conteúdos curriculares, na educação básica. Mais que desenvolver e aprimorar habilidades de pensamento algoritmico, são considerados aspectos sociais na produção do conhecimento e na relação com os estudantes. Ao longo do texto, as atividades realizadas são sumarizadas, assim como seus resultados.

\section{Introdução}

As tecnologias vêm ganhando cada vez mais espaço na sociedade, mudando a forma como interagimos como o mundo. Nesse contexto, é requerido dos cidadãos desenvolver diferentes habilidades, dentre elas o pensamento computacional (WING, 2006). Diversos estudos reportam a necessidade do desenvolvimento dessa habilidade computacional desde a educação básica, oportunizando aos estudantes conhecerem mais sobre a área, além de desfazer estereótipos existentes, provenientes de informações equivocadas, quanto aos interesses e aplicações da Ciência da Computação (FRANÇA et al., 2013).

$\mathrm{Na}$ literatura é possível identificar diversas ferramentas que podem apoiar o desenvolvimento do pensamento computacional. No levantamento realizado por Bombasar et al. (2015), o LEGO Mindstorms, o qual permite criar robôs que executam funções básicas préprogramadas, está na lista dos mais utilizados nos estudos analisados. Tendo em vista esse dado e o potencial da robótica enquanto recurso que pode potencializar a aprendizagem e a criatividade das crianças (PAPERT, 2008), propõe-se neste trabalho a exploração do pensamento computacional, no ensino médio, por meio da robótica livre. Tal abordagem é definida por César (2013) como sendo um conjunto de processos de ensino-aprendizagem que 
utiliza kits pedagógicos e artefatos cognitivos baseados em soluções livres e em sucatas como tecnologias de mediação para a construção do conhecimento.

Almeja-se com isso, instigar o senso de responsabilidade dos estudantes, canalizando seu conhecimento na construção de artefatos robóticos, a partir de sucata eletrônica, que podem impactar na vida das pessoas; além de apoiar o seu processo de desenvolvimento do pensamento computacional. Nesse sentido, este artigo descreve uma experiência vivenciada em uma escola pública estadual de Pernambuco, apoiando a democratização do conhecimento de Computação e outras áreas, por meio da abordagem empregada.

\section{A Experiência Vivenciada}

O objetivo deste trabalho é promover a exploração do pensamento computacional no ensino médio, pela produção de artefatos robóticos significativos a partir de sucata eletrônica. Nas subseções seguintes são descritos o contexto em que a pesquisa foi vivenciada, assim como os participantes e as atividades desenvolvidas.

\subsection{Contexto e Participantes}

Esta pesquisa foi realizada em uma Escola Estadual de Referência em Ensino Médio de Pernambuco. O projeto iniciou-se em 2017, tendo continuidade em 2018. Neste artigo, serão apresentadas as experiências vivenciadas em 2017. Os estudantes interessados em participar das oficinas realizaram sua inscrição por meio de um formulário eletrônico, que teve seu link disponibilizado nos quadros de aviso da escola. A partir das informações fornecidas o planejamento do curso foi realizado.

\subsection{Execução}

Os encontros, com carga horária total de $42 \mathrm{~h}$, ocorreram às segundas-feiras, das $13 \mathrm{~h}$ às $15 \mathrm{~h}$ no laboratório de informática da escola e foram guiados por licenciandos em Computação. No primeiro momento, a proposta das oficinas foi apresentada, como também o contrato de convivência foi construído com os estudantes. Também, eles puderam confeccionar desenhos de robôs que desejavam construir ao longo do curso, que atendessem a problemas identificados na escola ou em seu entorno.

Nos encontros seguintes diversos recursos foram utilizados, visando desenvolver habilidades de pensamento computacional, como também conscientizar os estudantes quanto aos possíveis impactos no lixo eletrônico no meio ambiente. Dentre eles, destacam-se: i) atividades de computação desplugada ${ }^{1}$; ii) vídeos sobre gambiologia; iii) Jabuti Edu²; iv) Hora do Código $^{3}$; e v) sucata eletrônica.

Além da experiência em sala de aula, os estudantes puderam participar de um campeonato de robô de sumô, recebendo o apoio das professoras de Química e Matemática, no que diz respeito ao incentivo e acompanhamento durante a competição. Também foram convidados a participar de uma Feira de Conhecimento, compartilhando suas experiências no curso. Em ambos os casos, os estudantes foram incentivados a avaliarem suas participações nas atividades e possíveis relações com os projetos.

\footnotetext{
${ }^{1} \mathrm{http}: / /$ csunplugged.org/

2 https://jabutiedu.org/

${ }^{3} \mathrm{http}: / /$ programae.org.br/horadocodigo/
} 
VIII Congresso Brasileiro de Informática na Educação (CBIE 2019)

Anais do XXV Workshop de Informática na Escola (WIE 2019)

Outro ponto que merece destaque é a visita ao Centro de Desenvolvimento de Colaboradores Robô Livre - Softex Recife e ao Laboratório de Objetos Conectados Urbanos L.O.U.CO, onde puderam conhecer soluções inovadoras para melhoria da qualidade de vida das pessoas, como também apresentarem e aperfeiçoarem as ideias de seus projetos, concebidas durantes as aulas. No último encontro, estava prevista a culminância dos projetos, planejada pelos próprios estudantes. Após sua realização, foi disponibilizado um formulário eletrônico para que os participantes pudessem avaliar o curso ofertado.

\section{Resultados e Discussões}

A proposta do projeto na escola veio por meio de uma necessidade de atender ao seu PPP e ao PROEMI, atrelado ao desejo de movimentar o laboratório de informática que estava desativado. A partir disso, o projeto foi elaborado atendendo aos anseios da escola e dos estudantes, alinhado com a educação para o século XXI. O curso teve 13 estudantes matriculados. Três deles não estavam mais vinculados à escola. Ainda assim, decidiu-se mantêlos, tendo em vista suas motivações em participar espontaneamente do curso.

\subsection{Projetos Desenvolvidos pelos Estudantes}

Em relação aos projetos, foram desenvolvidos ao longo do curso o carrinho sumô, a lixeira inteligente, o sensor de fumaça e incêndio e o carrinho seguidor de linha, apresentados na Figura 1. Face a esses resultados ressalta-se o uso de sucata eletrônica na construção desses projetos, possibilitando o acesso dos estudantes ao conhecimento de Computação e de disciplinas curriculares, ainda que com poucos recursos.

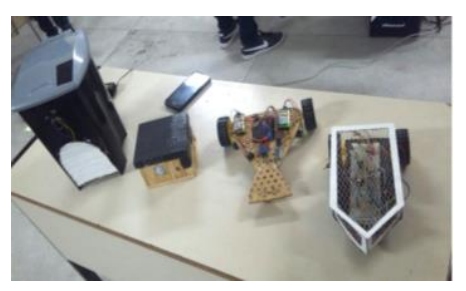

Figura 1. Projetos desenvolvidos

Durante a culminância dos protótipos dos projetos - que contou com a presença de pais, instrutores e orientadora do projeto, gestão escolar e professores - os estudantes apresentaram suas funcionalidades: i) carrinho sumô: montado com peças recicláveis, Arduino, sensores etc., teve o propósito de ser utilizado para o campeonato de robô sumô. Com este artefato seus criadores conseguiram avançar na primeira etapa do campeonato e depois foram desclassificados por não construírem a engrenagem do carrinho para fazê-lo andar; ii) lixeira inteligente: identifica lixo orgânico e inorgânico por meio de um sensor ultrassônico. Caso o lixo seja inorgânico a tampa da lixeira abre. Caso contrário, permanece fechada; iii) sensor de fumaça e incêndio: o projeto teve o objetivo de ser criado para ajudar pessoas idosas, em situação de perigo, como: identificação de vazamento de gás butano ou na ocorrência de algum princípio de incêndio na localidade; e iv) carrinho seguidor de linha: teve como proposta materializar a compreensão da montagem e programação do carrinho apenas com eletrônica básica. Assim, o carrinho anda apenas em cima de uma linha preta, que pode ser uma fita isolante. Caso a linha acabe ou ele vá para outra direção, deve parar imediatamente.

Diante desses resultados, destaca-se a proposição de projetos, pelos estudantes, que podem impactar positivamente sobre a vida das pessoas, tais como a lixeira inteligente e o sensor de fumaça e incêndio. Nesse sentido, a metodologia adotada desde o início do curso 
VIII Congresso Brasileiro de Informática na Educação (CBIE 2019)

Anais do XXV Workshop de Informática na Escola (WIE 2019)

pode ter contribuído com esses resultados: em sala, trabalhou-se com exemplos relacionados, e as visitas a ambientes como o L.O.U.CO podem ter inspirado ideias como as concebidas.

\subsection{Pensamento Computacional}

Em relação à Computação, especialmente pensamento computacional, foi possível o trato com diferentes conceitos: i) decomposição: uma vez concebidos os robôs, os estudantes tiveram que identificar suas partes menores, passíveis de serem construídas em cada encontro; ii) reconhecimento de padrões: as orientações que poderiam ser dadas aos robôs se assemelham às usadas pelos estudantes, tais como seguir para frente/trás, girar para direita/esquerda, abrir/fechar; iii) abstração: além da manipulação com Arduino, os estudantes tiveram acesso à programação em blocos durante a Hora do Código, trabalhando assim com a programação em diferentes níveis de abstração; iv) algoritmos: em atividades desplugadas os estudantes foram iniciados à prática de programação. Além disso, simularam o funcionamento do computador, seguindo instruções, e puderam definir e programar instruções precisas para seus robôs.

Alinhado à teoria construcionista que embasou este trabalho, foi possível observar nas respostas dos estudantes ao questionário a sua percepção de expressão no mundo por meio da robótica: P02: "a robótica deu uma oportunidade de desafiar-me a fazer coisas que nunca fiz, e uma oportunidade de tentar sempre se superar e você olha pra si e dizer que consegue fazer isso". Nesse sentido, mais que usar, um dos estudantes percebe-se capaz de criar e modificar o seu entorno a partir dos conhecimentos construídos nas oficinas.

\subsection{Motivação dos Estudantes e Desempenho em Disciplinas Curriculares}

Em relação ao questionário respondido pelos concluintes, ele continha questões sobre a motivação deles para inscrever-se no curso; se suas expectativas foram atendidas; o que aprendeu; a identificação de relações entre o que foi visto no curso e conteúdos curriculares; dificuldades tidas; pretensão de seguir estudos na área; indicação do curso a colegas e sugestões em geral.

Sobre a motivação, a maioria reportou o desejo de aprender novos conceitos, havendo dois com interesse de seguir carreira na área de robótica. Todos informaram que suas expectativas com o curso foram atendidas. Em relação ao que mais aprenderam no curso, podese destacar a reutilização de materiais que comumente são descartados, como também o trabalho em equipe, conforme pode ser observado nas falas a seguir: i) P02: "Aprendi que nem tudo é lixo, mas sim uma forma de se, reaproveitado para servir como uma outra obra, aprender a construir e montar robôs."; ii) P04: "A principalmente recicla objetos quebrados, aprendi a trabalha em equipe”. Ainda houve resposta associada à aprendizagem de conceitos de computação, como números binários.

No que se refere à relação entre os conceitos vistos e as disciplinas curriculares, a maioria das respostas cita a Matemática. Há menção também à Física, Biologia e Artes. Em relação às dificuldades tidas, são citadas, dentre outras, o entendimento do funcionamento de um programa. Por outro lado, um dos participantes reporta a importância do trabalho colaborativo nos processos de ensino e aprendizagem, enfatizando que não teve dificuldade devido à ajuda de seus colegas: P05: "não, sempre recebi ajuda dos colegas".

A maioria reporta que pretende seguir os estudos na área e todos disseram que indicariam o curso de robótica a seus colegas, enfatizando a necessidade desse conhecimento a todos, independente de seu futuro campo de atuação: P03: "Sim, pois é algo que não apenas importa para quem irá seguir essa carreira, é algo que você irá levar em toda sua vida, em todos o momentos, afinal nos encontramos na era globalizada." 
VIII Congresso Brasileiro de Informática na Educação (CBIE 2019)

Anais do XXV Workshop de Informática na Escola (WIE 2019)

Ademais, uma das mães presentes na culminância reportou que após o envolvimento do filho com as oficinas ele teve mais iniciativa para estudar, demonstrando mais interesse em frequentar a escola. Com isso, deseja que ele participe de mais ações como a realizada.

Também, segundo relatos dos professores das disciplinas curriculares Matemática e Química, percebeu-se que os participantes das oficinas se empenharam mais em suas aulas, melhorando seu comportamento e desempenho nas atividades avaliativas. Destaca-se também o convite da Secretaria de Educação de Pernambuco - Gerência Regional de Educação à escola para apresentação das práticas exitosas ao longo do ano, e o projeto aqui reportado foi contemplado por ter impacto e resultados na comunidade escolar.

\subsection{Dificuldades Observadas}

Uma das dificuldades encontradas foi a evasão dos estudantes. Um dos fatores que pode ter contribuído para isso foi o fato de as oficinas serem realizadas no contraturno. Um outro obstáculo observado diz respeito ao acesso à internet: durante o evento Hora do Código, em muitos momentos em que os estudantes faziam a construção dos códigos, os computadores ficavam sem acesso à rede requerendo refazer a programação. Ressalta-se, no entanto, a motivação dos estudantes para execução das atividades propostas, realizando algumas delas em casa ou na lan house.

\section{Considerações finais}

Neste artigo foi descrito um relato de experiência com robótica livre, atrelado ao pensamento computacional, no ensino médio. Considera-se que o tempo das oficinas foi pouco, no entanto, suficiente para trabalhar com os estudantes conceitos de boa convivência, contrato didático, trabalho em equipe; além de atividades envolvendo pensamento computacional e robótica livre, na escola e fora desse ambiente. Ao longo dessas interações os estudantes puderam projetar e avaliar suas propostas de artefatos robóticos utilizando sucata eletrônica, aperfeiçoando suas ideias, ao mesmo tempo em que construíam conhecimento sobre Computação, de forma interdisciplinar.

Como trabalhos futuros almeja-se analisar o impacto das atividades no desenvolvimento de habilidades de pensamento computacional, como também de que maneira o conhecimento construído é usado pelos estudantes em disciplinas curriculares. Essas questões merecem investigação, uma vez que o discurso sobre a necessidade do pensamento na educação básica tem como um de seus pilares a aplicação desse conhecimento em áreas além da Computação.

\section{Referências}

Bombasar, J. R., Santiago, R., Miranda, E. M., Raabe, A. L. A. (2015). "Ferramentas para o Ensino-Aprendizagem do Pensamento Computacional: onde está Alan Turing?". In: Anais do XXVI Simpósio Brasileiro de Informática na Educação.

César, D. R. (2013). Robótica pedagógica livre: uma alternativa metodológica para a emancipação sociodigital e a democratização do conhecimento. Tese de Doutorado. UFBA.

França, R. S., Silva, W. C., \& Amaral, H. J. C. (2013). "Computino: um jogo destinado à aprendizagem de Números Binários para estudantes da educação básica”. In: Anais do XXI Workshop sobre Educação em Computação.

Papert, Seymour. (2008) A Máquina das Crianças: repensando a escola na era da informática. Porto Alegre: Artmed.

Wing, J. M. (2006). Computational thinking. Communications of the ACM, 49(3), 33-35. 